\title{
Tracking of Dietary Intake and Factors Associated with Dietary Change from Early Adolescence to Adulthood: The ASH30 Study
}

\author{
Amelia A. Lake ${ }^{a}$ Ashley J. Adamson ${ }^{a}$ Angela M. Craigie ${ }^{a} \quad$ Andrew J. Rugg-Gunn $^{a}$ \\ John C. Mathers ${ }^{\text {b }}$ \\ ${ }^{a}$ Human Nutrition Research Centre, Institute of Health and Society, \\ ${ }^{\mathrm{b}}$ Human Nutrition Research Centre, Institute for Ageing and Health, Newcastle University, Newcastle upon Tyne, UK
}

\section{Key Words}

Food intake - Adolescence - Adulthood - Tracking ·

Factors associated with change

\section{Summary}

Objective: This paper describes the tracking of food intake from adolescence to adulthood according to location as an adult (at the time of the follow-up study) and gender. Additionally this paper explores factors associated with change in food intake. Method: Two 3-day food diaries, demographic and socio-economic information were collected in 1980 and 2000 from the same 198 participants (81 male, 117 female). Foods consumed were assigned to the five categories in The Balance of Good Health (BGH) food model. The tracking of food intake was assessed using Pearson correlation analyses. In 2000 two questionnaires were completed. Demographic and key attributional factors, derived from closed and open-ended responses to the questionnaire, were compared with measured change using regression analysis. Results: There was significant tracking of intake by food group from adolescence to adulthood according to location as an adult and gender. Eight combinations of descriptive variables and questionnaire factors were associated with change in intake of four of the five BGH food groups. Conclusion: Between adolescence and adulthood, dietary tracking is influenced by variables including gender and location. Attributions for change in food intake were associated with measured changes in food intake. In order to support healthier eating habits, it is important to be aware of factors contributing to changes in food intake, such as parental influences and perceived influences of time and work.

\section{Introduction}

Obesity in young people is of great concern; it is difficult to treat, and there is a high risk of persistence into adulthood [1]. In addition to body mass index (BMI) [2], risk factors for poor health such as unhealthy food intake [3] and sedentary behaviour [4, 5] 'track' into adulthood. Tracking is defined as the 'preservation of relative position' [6]. Obese adolescents are likely to have poorer health and reduced life expectancy through increased risk of associated disease [7]. Prevention of obesity in young people is a high priority [8]. During the period of transition from adolescence to adulthood, individuals experience growing independence from parents [9], form their own eating habits, move from school into employment or further education [10], and shape their identity, values, beliefs and morals [11]. These processes contribute to their food choices and may precipitate or reinforce behaviour changes. Numerous factors influence the complex process of dietary change from adolescence to adulthood [12]. These factors include demographic, economic, socio-cultural and health factors. There are known variations in UK dietary intake by socio-economic status [13], geographical location [14, 15], gender [13], and attitudes and beliefs [16]. Less is known about individual's attributions and perceptions for their dietary intake or dietary change - a unique focus of this paper and study.

Previous studies have reported the tracking of diet from early adolescence to adulthood, but the methods (including time for follow-up) and analyses used have been inconsistent. The Amsterdam Growth and Health Longitudinal Study measured the dietary intake (nutrients and food groups) of 200 male and female subjects at 8 time points over 24 years between ages 13 and 36 years [17]. They reported that from

\section{KARGER}

Fax +497614520714

Information@Karger.de

www.karger.com (c) 2009 S. Karger GmbH, Freiburg

Accessible online at:

www.karger.com/ofa 
adolescence to adulthood there were low to moderate trends for tracking of dietary intake and suggested that whilst diet stabilises with increasing age it does not stabilise during adolescence. Similarly, the Penn State Young Women's Health study of 81 females who were followed from age 12 to 18 years found that dietary patterns did not remain stable through adolescence [18]. Between age 15 and 22 years the Young Hearts Study in Northern Ireland [19] found that tracking of energy (MJ/day) and nutrient intakes (expressed per MJ/day) was only poor to fair (all $\kappa<0.25$ ). Over a shorter time period, Kelder et al. [20] found that from 10-11 years to 16-17 years, healthy food choices tracked in 2,376 children in the USA. While the authors acknowledged measurement issues in this sample, their results regarding tracking of food choices, smoking, and physical activity are interesting.

The ASH30 Study aimed to explore both tracking of and change in food intake from adolescence to adulthood and to determine what factors influenced the change or continuity of dietary behaviour. The analyses presented here seek to describe the tracking of food intake according to location as an adult (at the time of the follow-up study) and gender and to explore factors influencing dietary change.

\section{Participants and Methods}

\section{Participants and Dietary Surveys}

Pupils aged $11-12$ years $(n=784)$ attending seven middle schools in Northumberland, North East England, were invited to take part in a dietary study. Of those invited to participate 466 volunteered and 405 completed all aspects of the study (51.7\% of those invited) [21]. Between 1997 and 2000 a range of methods were used to contact the 405 original participants: sending letters from the Medical Research Unit of the Office of National Statistics (ONS) to those who had been located, organising reunion parties, placing articles in local media, and by 'word of mouth' [3]. The result was that 298 of the original cases were retraced in the UK. Of these, 208 consented to take part in a subsequent study in 2000/2001, and 198 completed all aspects of the study when aged 32-33 years in 2000 [3].

Two 3-day food diaries were collected at both time points (20 years apart); foods consumed at both time points were assigned to one of the five food groups from The Balance of Good Health (BGH) food guide [22] (this has now been replaced by new guidance [23], but the proportions remain unchanged) and expressed as a percentage contribution to total food weight according to specifications made by Gatenby et al. [24]. The BGH model, developed in 1994 as a nationally recognisable and authoritative food guide to be used in health promotion, recommends that a balanced diet should consist of approximately $33 \%$ fruit and vegetables, $33 \%$ bread, other cereals and potatoes, $15 \%$ milk and dairy products, $12 \%$ meat, fish and alternatives, and $8 \%$ foods containing fat and/or sugar [24]. Using this novel method of dietary analysis allowed the data to be compared with national dietary guidelines and was useful in providing feedback to the participants (data not presented in this paper).

Questionnaire data were not collected in 1980, but in 2000 two selfcompletion questionnaires were used to obtain the individual's perceptions of and their attributions for dietary change and change in eating habits and food choice between adolescence to adulthood [12]. Two independent qualitative analyses of the open-ended questionnaire responses were carried out to derive the dominant themes using content analysis [25] with QSR N5 NUD*IST.

\section{Socio-Economic Information}

Demographic information was derived from the questionnaire. To compare socio-economic status at both time points, the 1970 Registrar General's [26] definitions were used, based on the head of household occupations in 1980 [21] and 2000. Socio-economic status was divided into four groups: group 1, (high), group 2, (middle), group 3 (low), group 4 (unclassifiable: retired, unemployed and unknown).

\section{Analysis}

Analyses of quantitative data were carried out using SPSS 15.0. All quantitative data were checked for normality, and all data used were normally distributed. The validity of the food intake data was tested for low energy reporting [27], and all 198 participants were included in the analysis. Dietary change was expressed as the difference in percentage contribution made by each $\mathrm{BGH}$ food group to total weight of food eaten comparing 2000 with 1980 (2000-1980). Changes in dietary intake of participants were compared using t-tests (significance $\mathrm{p}<0.05$ ). The tracking of percentage contribution to total food intake was assessed using Pearson correlation analyses. Forward selection step-wise regression analysis was used to determine which demographic and questionnaire variables (attributions for change) were associated with change in intake of each food group. Demographic variables used were: gender, location in 2000, social group in 1980/2000, and social group mobility between 1980 and 2000. The eight dominant themes emerging from the questionnaire were: influence of partners, influence of parents, influence of children, awareness of nutrition and health, employment, time, convenience, and finance [12].

Ethical approval was obtained from the UK Multi-Centre Research Ethics Committee and from 50 Local Research Ethics Committees.

\section{Results}

Excluding the four respondents who did not complete all aspects of the 2000 study, the 198 respondents in the 2000 study were compared with the 203 non-participants. Significantly more female than male subjects participated in the 2000 study $\left(\chi^{2}=6.57 ; p=0.010\right)$. Participants in the 2000 study were significantly more likely to come from the highest and middle social groups compared with the individuals who did not participate in the 2000 study $\left(\chi^{2}=12.59 ; p=0.006\right)$. There were no significant differences in percentage contribution made by each of the $\mathrm{BGH}$ food groups to total food weight of food consumed in 1980 between the 203 non-participants and the 198 participants in the 2000 study.

198 participants (81 male, 117 female) completed all aspects of the survey. The mean age of participants in 1980 was $11.6 \pm 0.30$ years (mean \pm SD) and in 2000 was $32.5 \pm 0.33$ years. After 20 years, 70\% (139) of the original survey participants were still resident in Northumberland, 16 (8\%) had moved to nearby Tyne and Wear, and the remaining 43 (22\%) had moved to elsewhere in the UK (table 1). Outside Northumberland and Tyne and Wear, the largest grouping of participants was within London $(n=6)$. For the purpose of analysis the participants from nearby Tyne and Wear have been combined with the Northumberland residents to give a local sample population of $78 \%$. In 2000 the majority (79\%) were living with their partner and/or children, and $4 \%$ were living with their parents (table 1). The majority had experienced some 
Table 1. Location and living arrangements of participants in $2000(\mathrm{n}=198)$

\begin{tabular}{|c|c|c|c|c|c|c|c|}
\hline & \multicolumn{3}{|c|}{ Male } & \multicolumn{2}{|c|}{ Female } & \multicolumn{2}{|c|}{ Total } \\
\hline & $\mathrm{n}$ & & $\%$ & $\mathrm{n}$ & $\%$ & $\mathrm{n}$ & $\%$ \\
\hline Total & 81 & 41 & & 117 & 59 & 198 & 100 \\
\hline Living in Northumberland or Tyne and Wear & 60 & 74 & & 94 & 80 & 154 & 78 \\
\hline Living elsewhere in the UK & 21 & 26 & & 23 & 20 & 44 & 22 \\
\hline Living with anyone* & 71 & 88 & & 109 & 93 & 180 & 91 \\
\hline Living alone & 10 & 12 & & 8 & 7 & 18 & 9 \\
\hline Living with others $* *$ & 2 & 3 & & 0 & 0 & 2 & 1 \\
\hline Living with parents & 5 & 6 & & 3 & 3 & 8 & 4 \\
\hline Living with children and partner & 38 & 47 & & 66 & 56 & 104 & 53 \\
\hline Living with children only & 2 & 3 & & 9 & 8 & 11 & 6 \\
\hline Living with partner only & 24 & 30 & & 28 & 24 & 52 & 26 \\
\hline Living with parents and children & 0 & 0 & & 2 & 2 & 2 & 1 \\
\hline Living with parents and siblings & 0 & 0 & & 1 & 1 & 1 & 1 \\
\hline
\end{tabular}

*Anyone includes parents, partners, children or other people.

**Others includes all others apart from parents, partners and children.
Table 2. Social group classification in 1980 and 2000 according to 1970 classifications [26] $(\mathrm{n}=198)$

\begin{tabular}{|c|c|c|c|c|c|c|c|c|}
\hline & \multicolumn{8}{|c|}{ Social group by 1970 classification } \\
\hline & \multirow{2}{*}{\multicolumn{2}{|c|}{$\begin{array}{l}1 \\
\text { High }\end{array}$}} & \multirow{2}{*}{\multicolumn{2}{|c|}{$\begin{array}{l}2 \\
\text { Middle }\end{array}$}} & \multirow{2}{*}{\multicolumn{2}{|c|}{$\begin{array}{l}3 \\
\text { Low }\end{array}$}} & \multirow{2}{*}{\multicolumn{2}{|c|}{$\begin{array}{l}4 \\
\text { Unclassified }\end{array}$}} \\
\hline & & & & & & & & \\
\hline & $\mathrm{n}$ & $\%$ & $\mathrm{n}$ & $\%$ & $\mathrm{n}$ & $\%$ & $\mathrm{n}$ & $\%$ \\
\hline 1980 & 52 & 26 & 91 & 46 & 45 & 23 & 10 & 5 \\
\hline 2000 & 86 & 43 & 73 & 37 & 32 & 16 & 7 & 4 \\
\hline
\end{tabular}

Table 3. Social groups in 1980 and 2000 (1970 classifications [26]) according to location in 2000 $(\mathrm{n}=198)$

\begin{tabular}{|c|c|c|c|c|c|c|c|c|}
\hline \multirow[t]{4}{*}{ Location in 2000} & \multicolumn{8}{|c|}{ Social group by 1970 classification } \\
\hline & \multirow{2}{*}{\multicolumn{2}{|c|}{$\begin{array}{l}1 \\
\text { High }\end{array}$}} & \multirow{2}{*}{\multicolumn{2}{|c|}{$\begin{array}{l}2 \\
\text { Middle }\end{array}$}} & \multirow{2}{*}{\multicolumn{2}{|c|}{$\begin{array}{l}3 \\
\text { Low }\end{array}$}} & \multirow{2}{*}{\multicolumn{2}{|c|}{$\begin{array}{l}4 \\
\text { Unclassified }\end{array}$}} \\
\hline & & & & & & & & \\
\hline & $\mathrm{n}$ & $\%$ & $\mathrm{n}$ & $\%$ & $\mathrm{n}$ & $\%$ & $\mathrm{n}$ & $\%$ \\
\hline \multicolumn{9}{|l|}{ Social group $1980^{*}$} \\
\hline Northumberland and Tyne and Wear & 39 & 25 & 68 & 44 & 39 & 25 & 8 & 5 \\
\hline Elsewhere & 13 & 30 & 23 & 52 & 6 & 14 & 2 & 5 \\
\hline \multicolumn{9}{|l|}{ Social group $2000^{* *}$} \\
\hline Northumberland Tyne and Wear & 57 & 37 & 60 & 39 & 31 & 20 & 6 & 4 \\
\hline Elsewhere & 29 & 66 & 13 & 30 & 1 & 2 & 1 & 2 \\
\hline
\end{tabular}

*No significant difference between social group in 1980 and location in 2000.

**Significant difference between social group in 2000 and location in $2000\left(\chi^{2}=14.41 \mathrm{p}=0.002\right)$. change in social grouping: $43 \%$ moved up at least one social group, and $22 \%$ moved down at least one social group, while $35 \%$ remained in the same social group [3]. Further details of social groups in 1980 and 2000 are presented in table 2.

Table 3 illustrates the social groupings of individuals in 1980 and 2000 according to their location in 2000. More participants in the high and middle groups in 1980 were living elsewhere in the UK in 2000, compared with the low and unclassified groups who remained in Northumberland and Tyne and Wear in 2000. In 2000, 37\% of these individuals who had remained in Northumberland and Tyne and Wear were in the highest social group, compared with $66 \%$ of the group who had moved to elsewhere in the UK (table 3). In 2000 those individuals who lived elsewhere had the highest proportion in the high and middle groups, and only 1 individual in each of the low and unclassified social groups $\left(\chi^{2}=14.41 ; p=0.002\right)$.

Table 4 illustrates the movement of social group according to location in 2000. A higher proportion (27\%) of those 
Table 4. Movement in social groups from 1980 and 2000 according to location in $2000(\mathrm{n}=198)^{*}$

\begin{tabular}{|c|c|c|c|c|c|c|c|c|}
\hline \multirow[t]{3}{*}{ Location in 2000} & \multicolumn{8}{|c|}{ Social groups movement } \\
\hline & \multicolumn{2}{|c|}{$\begin{array}{l}\text { Stayed in same } \\
\text { group }\end{array}$} & \multicolumn{2}{|c|}{$\begin{array}{l}\text { Moved up in } \\
\text { social group }\end{array}$} & \multicolumn{2}{|c|}{$\begin{array}{l}\text { Moved down in } \\
\text { social group }\end{array}$} & \multicolumn{2}{|c|}{ Total } \\
\hline & $\mathrm{n}$ & $\%$ & $\mathrm{n}$ & $\%$ & $\mathrm{n}$ & $\%$ & $\mathrm{n}$ & $\%$ \\
\hline Northumberland and Tyne and Wear & 52 & 34 & 61 & 40 & 41 & 27 & 154 & 78 \\
\hline Elsewhere & 17 & 39 & 24 & 55 & 3 & 7 & 44 & 22 \\
\hline Total & 69 & 35 & 85 & 43 & 44 & 22 & 198 & 100 \\
\hline
\end{tabular}

*Significant difference between social group movement from 1980 to 2000 and location in $2000\left(\chi^{2}=8.05 \mathrm{p}=0.018\right)$.

Table 5. Contributions (\%) of BGH food groups to total food weight in 1980 and $2000(\mathrm{n}=198)$

\begin{tabular}{|c|c|c|c|c|c|}
\hline BGH food group & Minimum & Maximum & Mean & Standard error & $\mathrm{p}$ value* \\
\hline \multicolumn{6}{|c|}{ Bread other cereals and potatoes } \\
\hline 1980 & 12.9 & 58.1 & 30.3 & 0.5 & \multirow[b]{2}{*}{0.349} \\
\hline 2000 & 11.7 & 46.6 & 29.7 & 0.5 & \\
\hline \multicolumn{6}{|c|}{ Foods containing fat and/or sugar } \\
\hline 1980 & 8.0 & 38.7 & 21.2 & 0.4 & \multirow[b]{2}{*}{0.01} \\
\hline 2000 & 0 & 39.5 & 12.4 & 0.4 & \\
\hline \multicolumn{6}{|l|}{ Fruit and vegetables } \\
\hline 1980 & 2.2 & 33.8 & 14.6 & 0.5 & \multirow[b]{2}{*}{0.01} \\
\hline 2000 & 3.9 & 53.9 & 25.2 & 0.8 & \\
\hline \multicolumn{6}{|c|}{ Meat, fish and alternatives } \\
\hline 1980 & 5.2 & 33.6 & 16.7 & 0.4 & \multirow[b]{2}{*}{0.494} \\
\hline 2000 & 4.2 & 37.2 & 17.0 & 0.5 & \\
\hline \multicolumn{6}{|c|}{ Milk and dairy foods } \\
\hline 1980 & 1.4 & 39.6 & 17.2 & 0.5 & \multirow[b]{2}{*}{0.031} \\
\hline 2000 & 0.4 & 47.3 & 15.6 & 0.6 & \\
\hline
\end{tabular}

who had remained in Northumberland and Tyne and Wear had moved down in social group, compared with those who moved to elsewhere in the UK $(7 \%)$.

\section{Intake and Changes in Food Group Intake from Early Adolescence to Adulthood}

Between 1980 and 2000 there was a large and significant increase in intake of fruit and vegetables $(10.6 \%$ units; $p<0.01)$ (table 5) [3]. There were significant reductions in the mean contribution to total food intake from foods containing fat and/or sugar $(8.8 \%$ units reduction; $\mathrm{p}<0.01)$ and a much smaller, but statistically significant, $(1.6 \%$ units $)$ fall in intake of milk and dairy foods $(\mathrm{p}=0.031)$. However, there were no significant changes in the proportions of food derived from bread, other cereals and potatoes as well as meat, fish and alternatives $\mathrm{BGH}$ food groups.

\section{Tracking of Food Intake from Early Adolescence to Adulthood}

There was evidence of significant correlation between 1980 and 2000 [3] of intakes of bread, other cereals and potatoes $(\mathrm{p}=0.002, \mathrm{r}=0.219)$, fruit and vegetables $(\mathrm{p}<0.001, \mathrm{r}=0.256)$, and meat, fish and alternatives $(\mathrm{p}=0.026, \mathrm{r}=0.158)$ as a proportion of total food intake. Intakes of milk and dairy foods and foods containing fat and/or sugar as a proportion of total food intake were not significantly correlated between 1980 and 2000. The findings of both tracking of intakes and the significant difference in intake of fruit and vegetables indicate that, although participants' intake of these foods increased significantly between 1980 and 2000, they tended to maintain their position in the distribution of intakes, i.e. those that had a higher or lower intake in 1980 relative to their peers maintained a higher or lower intake in 2000. 
Intake and Change in Food Group Intake from Early Adolescence to Adulthood according to 2000 Location

\section{Food Intake in 2000 according to Location}

Individuals who remained in Northumberland and Tyne and Wear 20 years after the original survey $(78 \%)$ had a significantly higher intake of bread, other cereals and potatoes (30.1 vs. $28.5 \% ; p=0.022)$ and significantly lower intakes of milk and dairy foods (16.7 vs. $19.2 \% ; \mathrm{p}=0.050)$ and fruit and vegetables $(24.0$ vs. $29.6 \%$; $p=0.002)$, than individuals who moved away to live elsewhere in the UK in 2000. The difference between intakes of foods containing fat and/ or sugar in those who lived elsewhere $(10.8 \%$ of total food weight) compared with those still resident in Northumberland $(12.8 \%$ of total food weight) approached significance $(\mathrm{p}=0.059)$.

\section{Change in Food Intake according to Location}

In common with the participants still living in Northumberland / Tyne and Wear, those who had moved away had significantly higher percentage contributions from fruit and vegetables $(p<0.001)$ and lower percentage contributions from foods containing fat and/or sugar $(\mathrm{p}<0.001)$. The 43 individuals who had moved elsewhere had a greater increase in percentage contribution from fruit and vegetables $(14.4 \%$ compared with $9.5 \%$ ) than those individuals who stayed in Northumberland or Tyne and Wear $(\mathrm{p}=0.010)$.

\section{Tracking of Food Intake according to Location}

For individuals still living in Northumberland and Tyne and Wear in 2000, contributions to total intake from bread, other cereals and potatoes, and fruit and vegetables in 1980 were significantly correlated with those in $2000(\mathrm{p}=0.004, \mathrm{r}=0.230$ and $\mathrm{p}=0.011, \mathrm{r}=0.203$ respectively).

For individuals living elsewhere in 2000, the percentage contribution to total intake from fruit and vegetables was strongly correlated $(\mathrm{p}=0.002 \mathrm{r}=0.455)$ between 1980 and 2000 , and this correlation of intake was stronger than for those individuals still living in Northumberland $(r=0.203)$. Although 1980 intakes of fruit and vegetables were not significantly different between those who remained and those who subsequently moved away $(14.5 \%$ of total food weight 'Northumberland residents' and $15.2 \%$ of total food weight 'elsewhere in the UK'), individuals who moved away had a stronger correlation of intake in fruit and vegetables.

\section{Food Intake and Changes in Food Group Intake from Early Adolescence to Adulthood according to Gender}

In 1980 intakes of all $\mathrm{BGH}$ food groups were similar for male and female participants. However, in 2000 fruit and vegetables made a significantly larger contribution to food intake among females $(27.0 \%$ compared with $22.7 \%(p=0.006)$ for male subjects). Conversely, in 2000 female participants had a significantly $(\mathrm{p}<0.001)$ lower intake of meat, fish and alternatives than did male subjects ( 15.5 vs. $19.2 \%)$. While male participants decreased significantly their intake of foods containing fat and/or sugar $(\mathrm{p}<0.001)$ and milk and dairy foods ( $p=0.003$ ) in 2000 compared with 1980 , their intakes of fruit and vegetables and meat, fish and alternatives increased significantly $(\mathrm{p}<0.001$ and $\mathrm{p}=0.006$, respectively). Similar to male participants, over the 20 years of the study female participants decreased their intake of foods containing fat and/or sugar while increasing significantly their intake of fruit and vegetables (both $\mathrm{p}<0.001$ ).

\section{Tracking of Intake of Food Groups according to Gender}

For male participants, the percentage contribution to total diet from meat, fish and alternatives in 2000 was significantly correlated with that in $1980(\mathrm{p}=0.008, \mathrm{r}=0.292)$. In other words, although intakes of this food group by male participants were higher on average in 2000 than in 1980, individual men tended to retain their relative position within the distribution of intakes for male participants over the period of study. For females, intakes of fruit and vegetables $(p=0.002, r=0.289)$ and of bread, other cereals and potatoes $(p=0.004, r=0.267)$ were both correlated significantly between 1980 and 2000 . Whilst percentage contributions from fruit and vegetables to total food intake increased significantly over the 20 years, female participants tended to maintain their relative position within the distribution of intakes for females.

\section{Factors Associated with Changes in Dietary Intake}

Although there was evidence of tracking of intake between 1980 and 2000, there was also evidence of considerable changes in intakes for individual participants. Key attributional factors, derived from closed and open-ended responses to the questionnaire, were associated with degree of change in intake over the 20 years [12]. These included awareness of nutritional messages, lack of time, employment, finance, parental influence (positive or negative), and the influence of partners (positive or negative) and/or children. We used responses to the questionnaire in 2000 [12] together with demographic and other characteristics of the study participants to identify those factors associated with change in intake of four BGH food groups between 1980 and 2000: fruit and vegetables, meat fish and alternatives, milk and dairy foods, and bread, other cereals and potatoes. None of the factors which we investigated were associated with change in intake of foods containing fat and/or sugar. The regression equations are given in table 6 .

Moving away from the Northumberland / Tyne and Wear area was significantly associated with a greater increase in 
fruit and vegetable intake in all four regression equations. After controlling for location in 2000, those who felt their parents to have had a positive influence on their change in diet tended to make smaller increases in their intakes of fruit and vegetables (equation $1, \mathrm{R}^{2}=0.087$ ), whereas greater increases were experienced in those who cited an increased awareness of nutrition and health (equation 2, $\mathrm{R}^{2}=0.072$ ), or who did not cite time as an explanation for changes in their diet (equation $3, \mathrm{R}^{2}=0.052$ ). Independent of location in 2000, social group in 2000 was a associated with change in fruit and vegetable intake, with the largest increases found in those with the highest social group in
Table 6. Factors associated with change in BGH food group intake*

\begin{tabular}{ll}
\hline Regression equation 1 for factors associated with change in intake of fruit and vegetables (2000-1980) & \\
\hline $\mathrm{Y}=11.2=-4.6(2.0) \mathrm{A}+8.8(2.6) \mathrm{B}+4.0(1.7) \mathrm{C}$ & $\mathrm{R}^{2}=0.087$ \\
Where: & \\
$\mathrm{Y}=\%$ Change in intake of fruit and vegetables $(2000-1980)$ & $\mathrm{p}=0.013$ \\
$\mathrm{~A}=1$ if living in Northumberland in 2000 otherwise $\mathrm{A}=0$ & $\mathrm{p}=0.003$ \\
$\mathrm{~B}=1$ if perceived a negative parental influence otherwise $\mathrm{B}=0$ & $\mathrm{p}=0.003$ \\
$\mathrm{C}=1$ if parents not cited otherwise $\mathrm{C}=0$ &
\end{tabular}

Regression equation 2 for factors associated with change in intake of fruit and vegetables (2000-1980)

$\mathrm{Y}=16.8=-4.6(1.6) \mathrm{A}+-4.2(1.9) \mathrm{B}$

$\mathrm{R}^{2}=0.072$

Where:

$\mathrm{Y}=\%$ Change in intake of fruit and vegetables (2000-1980)

$\mathrm{A}=1$ if awareness not cited otherwise $\mathrm{A}=0$

$\mathrm{p}=0.005$

$\mathrm{B}=1$ if living in Northumberland in 2000 otherwise $\mathrm{B}=0$

$\mathrm{p}=0.025$

Regression equation 3 for factors associated with change in intake of fruit and vegetables (2000-1980)

$\mathrm{Y}=12.1=3.3(1.7) \mathrm{A}+-4.87(1.9) \mathrm{B}$

$\mathrm{R}^{2}=0.052$

Where:

$\mathrm{Y}=\%$ Change in intake of fruit and vegetables (2000-1980)

$\mathrm{A}=1$ if time not cited otherwise $\mathrm{A}=0$

$\mathrm{p}=0.049$

$\mathrm{B}=1$ if living in Northumberland in 2000 otherwise $\mathrm{B}=0$

$\mathrm{p}=0.01$

Regression equation 4 for factors associated with change in intake of fruit and vegetables (2000-1980)

$\mathrm{Y}=10.4=-0.1(4.3) \mathrm{A}+-3.1(4.3) \mathrm{B}+-6.3(4.6) \mathrm{C}+3.6(1.7) \mathrm{D}$

Where:

$\mathrm{Y}=\%$ Change in intake of fruit and vegetables (2000-1980)

$\mathrm{A}=1$ if social group 20001 (highest) otherwise $\mathrm{A}=2$ or $\mathrm{A}=3$

$\mathrm{B}=1$ if social group 20002 (middle) otherwise $\mathrm{B}=0$

$C=1$ if social group 20003 (lowest) otherwise $C=0$

$\mathrm{p}=0.041$

$\mathrm{p}=0.041$

$\mathrm{D}=1$ if employment not cited otherwise $\mathrm{D}=0$

\begin{tabular}{ll}
\hline Regression equation 5 for factors associated with change in intake of meat, fish and alternatives (2000-1980) & \\
\hline $\mathrm{Y}=0.3=3.2(1.1) \mathrm{A}+-4.9(1.8) \mathrm{B}+-1.4(1.2) \mathrm{C}$ & $\mathrm{R}^{2}=0.083$ \\
Where: & \\
$\mathrm{Y}=\%$ Change in intake of meat, fish and alternatives (2000-1980) & $\mathrm{p}=0.003$ \\
$\mathrm{~A}=1$ male otherwise $\mathrm{A}=0$ & $\mathrm{p}=0.027$ \\
$\mathrm{~B}=1$ if perceived a negative parental influence otherwise $\mathrm{B}=0$ & $\mathrm{p}=0.027$ \\
$\mathrm{C}=1$ if parents not cited otherwise $\mathrm{C}=0$ & \\
\hline Regression equation 6 for factors associated with change in intake of meat, fish and alternatives $(2000-1980)$ & \\
\hline $\mathrm{Y}=-3.8=2.2(1.1) \mathrm{A}+1.7(2.9) \mathrm{B}+0.1(2.9) \mathrm{C}+4.4(3.1) \mathrm{D}+3.0(1.1) \mathrm{E}$ & $\mathrm{R}^{2}=0.098$ \\
Where: & \\
$\mathrm{Y}=\%$ Change in intake of meat, fish and alternatives $(2000-1980)$ & $\mathrm{p}=0.045$ \\
$\mathrm{~A}=1$ if awareness not cited otherwise $\mathrm{A}=0$ & $\mathrm{p}=0.051$ \\
$\mathrm{~B}=1$ if social group 20001 (highest) otherwise $\mathrm{B}=0$ & $\mathrm{p}=0.051$ \\
$\mathrm{C}=1$ if social group 20002 (middle) otherwise $\mathrm{C}=0$ & $\mathrm{p}=0.051$ \\
$\mathrm{D}=1$ if social group 20003 (lowest) otherwise $\mathrm{D}=0$ & $\mathrm{p}=0.006$ \\
$\mathrm{E}=1$ if male otherwise $\mathrm{E}=0$ &
\end{tabular}

Table 6 continued on next page 


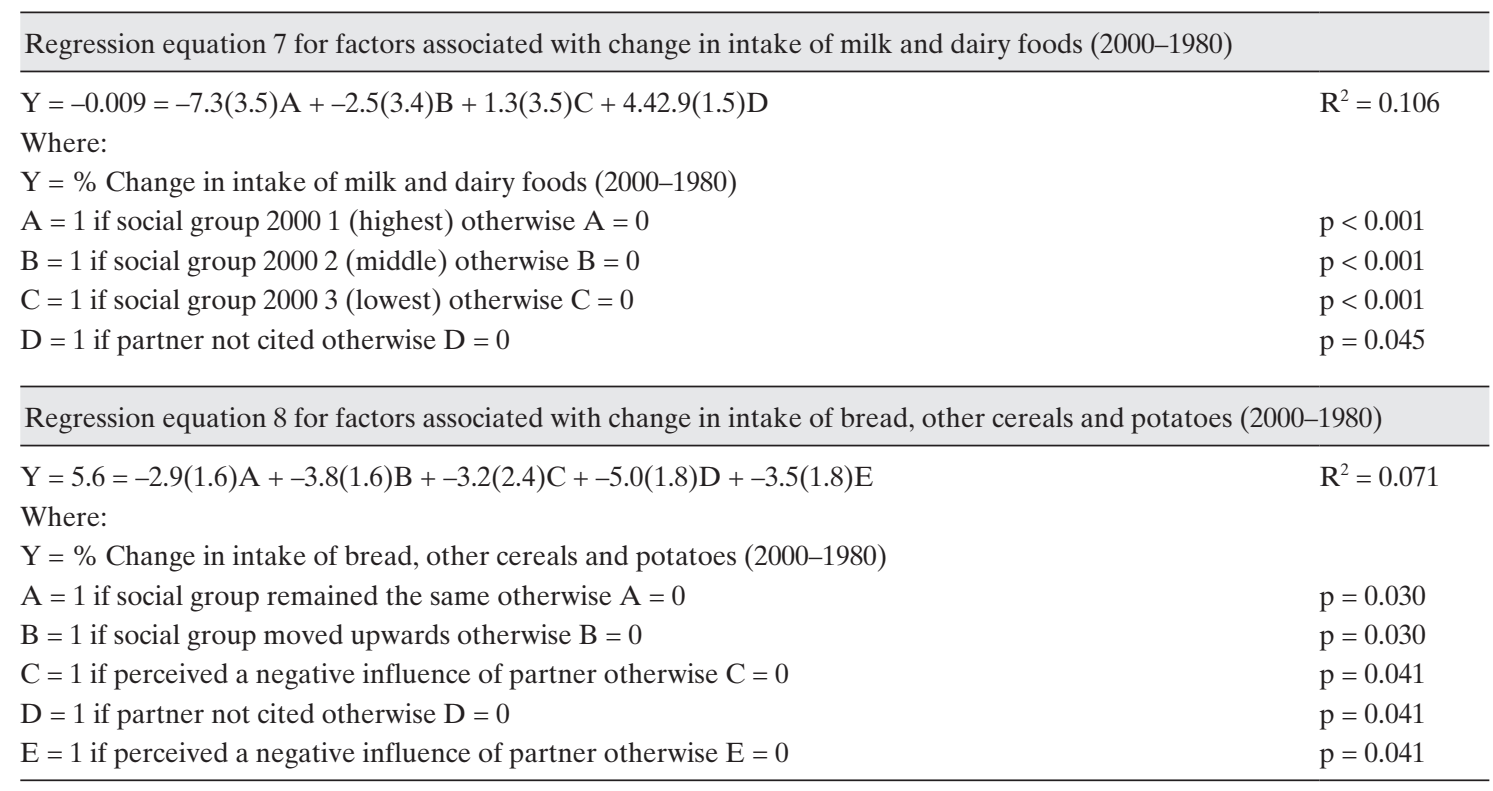

*Standard errors of the regression co-efficient are shown in parentheses in the table.

2000 (equation $4, \mathrm{R}^{2}=0.060$ ). After controlling for social group in 2000, those who cited employment as an indicator of dietary change were less likely to increase their fruit and vegetable intake.

Having controlled for gender, there were greater increases in intake of meat, fish and alternatives in those who perceived that their parents had a positive influence on their diet (equation $5, \mathrm{R}^{2}=0.083$ ). Equation 6 illustrates the influence of social group and not citing increased awareness of nutrition and health as an explanatory factor for dietary change in intake of meat, fish and alternatives $\left(\mathrm{R}^{2}=0.098\right)$.

Greater reductions in intakes of milk and dairy foods were predicted by having been in the highest social group in 1980 and among those who cited their partners (regardless of direction of influence) as having an influence on their dietary intake (equation 7).

The final equation, equation 8 , demonstrates the factors associated with change in intake of bread, other cereals and potatoes, with the greatest increases found in those who had moved down in social group and those who reported that their partner had a negative influence on their diet.

\section{Discussion}

Despite the major life changes that occur between early adolescence and adulthood, we have found strong evidence of tracking of food intake over this time. Additionally we have identified demographic and attributional factors which are associated with dietary change over time. These findings emphasise the importance of establishing healthy dietary behaviours in early adolescence.
Over the 20 years between the two surveys, the participants in the ASH30 Study had made many life changes, as could be anticipated; questionnaire responses indicated that daily routines involved work, responsibility, children and partners, that is a very different routine to that of an adolescent. $22 \%$ had moved away from the locality and were now living elsewhere in the UK. Only 4\% remained resident with their parents while the majority (79\%) were living with their partner and/or children. There were considerable changes in personal circumstances; only $35 \%$ remained in the same social group, most had changed social classification, $43 \%$ had moved up, and $22 \%$ moved down. These changes reflect secular changes across the UK where there has been a trend for increasing social group exemplified by more men and women in the professional and managerial occupations [28].

Our observed correlations of $r=0.256(p<0.001)$ for fruit and vegetable intake from age 12 to 32 years are similar to the Amsterdam Growth and Health Longitudinal Study which found tracking coefficients of $0.33(\mathrm{p}<0.001)$ and $0.27(\mathrm{p}<$ 0.001 ) for fruit and vegetable intake [29]. While this indicates that relative fruit and vegetables intake of 12-year-olds is, to some extent, predictive of relative intake in adulthood, our further analyses of other influences on dietary change add an interesting dimension to this discussion. For example, attributional factors as well as demographic factors were associated with change in fruit and vegetable intake, e.g. the relationship of participants' location in 2000 with their perceived nutritional awareness, direction of parental influence, their attribution of time, and employment. Attributions and perceptions of dietary change in relation to measured change in the ASH30 Study have been described in more depth [12]. This work highlights the value of using mixed methods in longitudinal studies [30]. 
Moving away from the North East of England was associated with greater increases in intakes of fruit and vegetables, as was being of a higher social grouping in 2000. Social grouping in 2000 was associated with change in intake of meat, fish and alternatives, and of fruit and vegetables. Individuals in the high social group had the greatest change while those in the low social group had the smallest change in intake of fruit and vegetables over the 20 years of the study. The Health Survey for England shows a strong social group gradient in fruit and vegetable consumption [15]. Moving to a higher social group was associated with a decrease in consumption of bread, other cereals and potatoes compared with those who stayed in the same or who moved down social grouping. Individuals whose social grouping decreased actually increased their intake of this food group over the 20 years. The National Food Survey [31] reported that consumers were purchasing cheaper types of bread that was more readily available in 2000 compared with 1975. Other cereal food consumption increased between 1975 and 2000, in particular cereal-based convenience foods such as pizza, pasta, cereal snacks, frozen cakes, and pastries. The relatively low cost of bread and increased purchasing of convenience foods may explain the increase in this BGH food group by those in the lower social groups

The most recent National Diet and Nutrition Survey [13] reported that men and women in households receiving benefits were less likely to consume some foods from the bread, other cereals and potatoes BGH food group such as soft grain bread, other bread (brown bread, bagels, continental breads), whole grain and high fibre breakfast cereals. Individuals in the lower social group may be relying on more traditional, and possibly cheaper, sources from this food group, while those in the higher social groups have moved on to fewer, more selected or costly, or 'healthier' foods from this group.

It is perhaps unsurprising that gender was associated with change in intake of meat, fish and alternatives and also milk and dairy foods. Meat consumption has been described as a marker of masculinity [32], and gender differences have been observed in attitudes to meat $[32,33]$ and meat intakes [13].

Although adiposity has not been discussed in this paper, BMI of respondents was recorded at both time points. In the ASH30 Study relative BMI, as an index of adiposity, tracked from adolescence to adulthood [2]. This is reflected in the significant tracking of food intake described in this paper and also in nutrient intake as described elsewhere [34].

The ASH30 Study is the first British study to assess longitudinal food intake between early adolescence and early to mid-adulthood. However, in addition to its strengths, the ASH30 Study has a number of limitations, including its relatively small sample size, lack of ethnic diversity (the cohort were largely a homogenous group of white individuals which was representative of the area in which they lived in 1980), and the fact that it was not designed as a longitudinal or tracking survey hence the 20-year gap between the two data collection points (a recent study by this group has explored tracking and change from age 11-12 to 17-18 years). Further, the individuals who took part in the follow-up study in 2000 were generally of a higher social grouping with a higher proportion of females than in the original 1980 study. Measuring dietary change in food terms is a difficult task, and the BGH model, a nationally accepted public health nutrition tool, was chosen as the best available food model. The grouping of foods using this model provides a picture of the diet as a whole, but has the disadvantage that the broad nature of the BGH food groups obscures potentially significant changes in types of food consumed, e.g. a change from whole milk to semi-skimmed milk, or replacement of sugar-rich, low-fibre breakfast cereals with unsweetened whole-grain alternatives. These limitations should be borne in mind when generalising findings from the ASH30 Study to other populations.

\section{Future Directions of the Research Field}

Longitudinal studies have tended to focus on the changes in individual behaviour. In the questionnaire responses the ASH30 participants attributed their change in food intake to a range of factors, including the change in availability and variety of foods over 20 years, their workplace food environment, their home food environment, and changes in general awareness of food and health. Little research exists on the broader changes in our environment over time. As more emphasis is placed on the environment and particularly the obesogenic environment [35], our current research is being designed to explore changes in individual dietary behaviour within an environmental context and specifically the food environment [36]. Future research exploring the relationship between food environment, food intake and adiposity requires a step-wise approach [37] and carefully designed longitudinal studies.

\section{Acknowledgements}

The authors thank the Wellcome Trust for funding this study (grant number 057995/Z/99/Z), Dr Allan Hackett, Liverpool John Moores University for the 1980 data collection, Megan Gibbons and Charlotte Wood for assistance with the 2000 ASH30 Study data collection, Dr. Robert Hyland for his qualitative expertise and advice, Professor John Matthews and Simon Webster for their statistical advice, and the participants for their contributions. The Occupational Information Unit of the Office of National Statistics assisted with the socio-economic coding.

\section{Disclosure}

Amelia A. Lake and Ashley J. Adamson are both funded by National Institute for Health Research Personal Awards. The views expressed in this publication are those of the author and not necessarily those of the NHS, NIHR or Department of Health. 


\section{References}

1 Summerbell CD, Ashton V, Campbell KJ, Edmunds L, Kelly S, Waters E: Interventions for treating obesity in children, Cochrane Database Syst Rev 2003;3:CDOO/872.

2 Craigie AM, Matthews JNS, Rugg-Gunn AJ, Lake AA, Mathers JC, Adamson AJ: Raised adolescent body mass index predicts the development of adiposity and a central distribution of body fat in adulthood: a longitudinal study. Obes Facts 2009; 2(3):150-156

3 Lake AA, Mathers JC, Rugg-Gunn AJ, Adamson AJ: Longitudinal change in food habits between adolescence (11-12 years) and adulthood (32-33 years): The ASH30 Study. J Public Health 2006;28:10-16.

$\checkmark 4$ Viner RM, Cole TJ: Who changes body mass between adolescence and adulthood? Factors predicting change in BMI between 16 year and 30 years in the 1970 British birth cohort. Int J Obes 2006;30: 1368-1374.

5 Auld MC, Powell LM: Economics of food energy density and adolescent body weight. Economica 2008;DOI: 10.1111/j.1468-0335.2008.00709.x.

6 Wardle J: Parental influence on children's diets Proc Nutr Soc 1995;54:747-758.

7 British Medical Association Board of Science and Education: Adolescent Health. London, BMA Publications Unit, 2003. www.bma.org.uk/images/ Adhealth_tcm41-19549.pdf.

8 Summerbell CD, Waters E, Edmunds LD, Kelly S, Brown T, Campbell KJ: Interventions for preventing obesity in children, Cochrane Database Syst Rev 2005;3 CD001871.

9 Rossow I, Rise J: Concordance of parental and adolescent health behaviours. Soc Sci Med 1994;38: 1299-1305.

10 Cullen KW, Koehly LM, Anderson C, Baranowski $\mathrm{T}$, Prokhorov A, Basen-Engquist K, Wetter D, Hergenroeder A: Gender differences in chronic disease risk behaviours through the transition out of high school. Am J Prev Med 1999;17:1-7.

-11 Bissonnette MM, Contento IR: Adolescents' perspectives and food choice behaviours in terms of the environmental impacts of food production practices: Application of a psychosocial model. J Nutr Educ 2001;33:72-82.

12 Lake AA, Rugg-Gunn AJ, Hyland RM, Wood CE, Mathers JC, Adamson AJ: Longitudinal dietary change from adolescence to adulthood: perceptions, attributions and evidence. Appetite 2004;42: 255-263.
13 Henderson L, Gregory J, Swan G: The National Diet and Nutrition Survey: Adults Aged 19-64 Years. Types and Quantities of Foods Consumed. London, Crown HMSO, 2002.

14 Leather S: Fruit and vegetables: consumption patterns and health consequences. Br Food J 1995;97: 10-17.

15 Doyle M, Hosfield N: Fruit and Vegetables Consumption: A Survey Carried Out on Behalf of the Department of Health (Health Survey for England 2001). London, Stationery Office, 2003.

16 Margetts BM, Thompson RL, Speller V, McVey D: Factors which influence 'healthy' eating patterns: results from the 1993 Health Education Authority Health And Lifestyle Survey in England. Public Health Nutr 1998;1:193-198.

17 Bertheke Post G, de Vente W, Kemper HCG, Twisk JWR: Longitudinal trends in and tracking of energy and nutrient intake over 20 years in a Dutch cohort of men and women between 13 and 33 years of age: the Amsterdam Growth And Health Longitudinal Study. Br J Nutr 2001;85:375-385.

18 Cardomone CD, Chinchilli VM, Johnson-Rollings N, Kieselhorst K, Stallings VA, Lloyd T: Longitudinal nutrient intake patterns of U.S. adolescent women: The Penn State Young Women's Health Study. J Adolesc Health 2000;26:194-204.

19 Gallagher AM, Robson PJ, Livingstone MBE, Cran GW, Strain JJ, Murray LJ, Savage JM, Boreham CAG: Tracking of energy and nutrient intakes from adolescence to young adulthood: the experiences of the Young Hearts Project, Northern Ireland. Public Health Nutr 2006;9:1027-1034.

20 Kelder SH, Perry CL, Klepp KI, Lytle LL: Longitudinal tracking of adolescent smoking, physical activity, and food choice behaviours. Am J Public Health 1994:84:1121-1126.

21 Hackett AJ, Rugg-Gunn AJ, Appleton DR, Eastoe JE, Jenkins GN: A 2-year longitudinal nutritional survey of 405 Northumberland children initially aged 11.5 years. Br J Nutr 1984;51:67-75.

22 Food Standards Agency: The Balance of Good Health. London, Food Standards Agency, 2001.

23 Food Standards Agency: The eatwell plate. London, Food Standards Agency, 2007, 2008. www. eatwell.gov.uk/healthydiet/eatwellplate/.

24 Gatenby SJ, Hunt P, Rayner M: The national food guide: development of dietetic criteria and nutritional characteristics. J Hum Nutr Diet 1995;8:323334.
25 Krippendorff K: Content Analysis: An Introduction to its Methodology. Beverly Hills, Sage, 1980.

26 Registrar General: Classification of Occupations 1970. Office of Population Censuses and Surveys. London, HMSO, 1970.

27 Goldberg GR, Black AE, Jebb SA, Cole TJ, Murgatroyd PR, Coward WA, Prentice AM: Critical evaluation of energy intake data using fundamental principles of energy physiology: 1 . Derivation of cut-off limits to identify under recording. Eur J Clin Nutr 1991;45:569-581.

28 Summerfield C, Babb P (eds): Social Trends National Statistics 2003, ed 33. London, TSO, 2003.

29 te Velde SJ, Twisk JWR, Brug J: Tracking of fruit and vegetable consumption from adolescence into adulthood and its longitudinal association with overweight. Br J Nutr 2007;98:431-438.

30 Lake AA, Hyland RM, Rugg-Gunn A, Mathers JC, Adamson AJ: Combining social and nutritional perspectives: From adolescence to adulthood (the ASH30 Study). Br Food J 2009; (in press).

31 Department for Environment Food and Rural Affairs and National Statistics: National Food Survey 2000. Annual Report on Food Expenditure, Consumption and Nutrient Intakes. London, The Stationery Office, 2001

32 Jensen KO, Holm L: Preferences, quantities and concerns: Socio-cultural perspectives on the gendered consumption of foods. Eur J Clin Nutr 1999; 53:351-359.

33 Holm L, Mohl M: The role of meat in everyday food culture: An analysis of an interview study in Copenhagen. Appetite 2000;34:277-283.

34 Craigie AC, Lake AA, Wood C, Gibbons M, RuggGunn AJ, Mathers JC, Adamson AJ: Tracking of adiposity and dietary intake from adolescence to adulthood: a longitudinal study. Int J Obes Related Metab Disorders 2003;27(suppl 9):T5:01-04.

35 Lake A, Townshend T: Obesogenic environments: exploring the built and food environments. J R Soc PromotHealth 2006;126:262-267.

36 Lake AA, Alvanides S, Adamson AJ, Townshend T, Stamp E: Diet, physical activity, sedentary behaviour and perceptions of the environment in young adults. J Hum Nutr Diet 2009; (in press).

37 Giskes K, Kamphuis CB, van Lenthe FJ, Kremers S, Droomers M, Brug J: A systematic review of associations between environmental factors, energy and fat intakes among adults: Is there evidence for environments that encourage obesogenic dietary intakes? Publ Health Nutr 2007:10:1005-1017. 